

\section{Gopenaccess}

Citation: Boukhris I, Smaoui S, Ennouri K, Morjene $\mathrm{N}$, Farhat-Khemakhem A, Blibech M, et al. (2020) Towards understanding the antagonistic activity of phytic acid against common foodborne bacterial pathogens using a general linear model. PLoS ONE 15(4): e0231397. https://doi.org/10.1371/journal. pone. 0231397

Editor: Filippo Giarratana, University of Messina, ITALY

Received: January 30, 2020

Accepted: March 22, 2020

Published: April 17, 2020

Peer Review History: PLOS recognizes the benefits of transparency in the peer review process; therefore, we enable the publication of all of the content of peer review and author responses alongside final, published articles. The editorial history of this article is available here: https://doi.org/10.1371/journal.pone.0231397

Copyright: ๑ 2020 Boukhris et al. This is an open access article distributed under the terms of the Creative Commons Attribution License, which permits unrestricted use, distribution, and reproduction in any medium, provided the original author and source are credited.

Data Availability Statement: All relevant data are within the manuscript and its Supporting Information files

RESEARCH ARTICLE

\title{
Towards understanding the antagonistic activity of phytic acid against common foodborne bacterial pathogens using a general linear model
}

\section{Ines Boukhris ${ }^{1}$, Slim Smaoui ${ }^{1}$, Karim Ennouri ${ }^{2}$, Nawres Morjene ${ }^{1}$, Ameny Farhat- Khemakhem ${ }^{1}$, Monia Blibech ${ }^{1}$, Othman A. Alghamdi ${ }^{3}$, Hichem Chouayekh $\circledast^{1,3 *}$}

1 Laboratoire de Microorganismes et de Biomolécules, Centre de Biotechnologie de Sfax, Université de Sfax, Sfax, Tunisia, 2 Laboratory of Amelioration and Protection of Olive Genetic Resources, Olive Tree Institute, University of Sfax, Sfax, Tunisia, 3 Department of Biological Sciences, Faculty of Sciences, University of Jeddah, Jeddah, Kingdom of Saudi Arabia

* hschouayekh@uj.edu.sa

\section{Abstract}

The increasing challenge of antibiotic resistance requires not only the discovery of new antibiotics, but also the development of new alternative approaches. Therefore, in the present study, we investigated for the first time the antibacterial potential of phytic acid (myo-inositol hexakisphosphate, IP6), a natural molecule that is 'generally recognized as safe' (FDA classification), against the proliferation of common foodborne bacterial pathogens such as Listeria monocytogenes, Staphylococcus aureus and Salmonella Typhimurium. Interestingly, compared to citric acid, IP6 was found to exhibit significantly greater inhibitory activity $(P<0.05)$ against these pathogenic bacteria. The minimum inhibitory concentration of IP6 varied from 0.488 to $0.97 \mathrm{mg} / \mathrm{ml}$ for the Gram-positive bacteria that were tested, and was $0.244 \mathrm{mg} / \mathrm{ml}$ for the Gram-negative bacteria. Linear and general models were used to further explore the antibacterial effects of IP6. The developed models were validated using experimental growth data for $L$. monocytogenes, $S$. aureus and $S$. Typhimurium. Overall, the models were able to accurately predict the growth of $L$. monocytogenes, $S$. aureus, and $S$. Typhimuriumin Polymyxin acriflavine lithium chloride ceftazidime aesculin mannitol (PALCAM), Chapman broth, and xylose lysine xeoxycholate (XLD) broth, respectively. Remarkably, the early logarithmic growth phase of $S$. Typhimurium showed a rapid and severe decrease in a period of less than one hour, illustrating the bactericidal effect of IP6. These results suggest that IP6 is an efficient antibacterial agent and can be used to control the proliferation of foodborne pathogens. It has promising potential for environmentally friendly applications in the food industry, such as for food preservation, food safety, and for prolonging shelf life. 
Funding: The Tunisian Government provided support via the Contract Program LMB-CBS (20152018) which includes several research projects, including this work. Funding was also received from the recently accepted International Cooperation Grant Research Project N ${ }^{\circ}$ UJ-02-009ICGR, funded by the University of Jeddah, though the grant is not specific to this study, but rather focusing on bio-composites for active packaging These provided funds were used to support the editing by a commercial and professional editing service as well as the publication fees of this manuscript in PLOS ONE.

Competing interests: The authors have declared that no competing interests exist

\section{Introduction}

Food safety is an important public health priority. Each year, around a third of the world population is infected by foodborne pathogens [1,2]. The highest incidence of foodborne diseases occurs in Africa [1], where more than 91 million people are estimated to fall ill each year, leading to around 137000 deaths [2]. L. monocytogenes is considered to be one of the most hazardous foodborne bacterial pathogens [3,4]. It is particularly problematic, as it can form biofilms and survive for long periods of time in a food processing environment [5]. L. monocytogenes causes human listeriosis, a rare disease associated with high rates of hospitalization and mortality $[6,7]$. The infection is mainly linked to the consumption of contaminated ready-to-eat foods, such as cheese and other dairy products, processed meats, salads, seafood, and raw eggs $[8,9]$. Another bacterium, S. aureus, which belongs to the Gram-positive Micrococcaceae family, is considered to be one of the most common causes of foodborne disease in the world [10]. This bacterium causes gastrointestinal illness by secreting a range of toxins, including staphylococcal enterotoxins [10-12]. S. aureus is also able to form biofilms on food-contact surfaces, which highly increases its stress tolerance and, thus, its persistence in food-related environments [13-16]. Salmonella is also considered to be among the most common foodborne pathogens [17]. It causes Salmonellosis, a disease that is linked to the consumption of contaminated meats, especially poultry products [17]. This disease is responsible for the largest number of hospitalizations and deaths due to foodborne pathogens [18].

In order to prevent the transmission of foodborne disease, the food industry uses a variety of methods, which can be physical (temperature, radiation), chemical (bleach, alcohol, iodine) or chemotherapeutic (antibiotics) [19, 20]. However, several studies have suggested that synthetic sanitizers can have significant side effects, such as bleaching and the formation of toxic compounds [21]. In addition, the growing rate of antimicrobial resistance in foodborne bacterial pathogens is also becoming a major concern for food safety and one of the disquieting threats to global human health [22]. For this reason, the World Health Organization (WHO) recommended that breeders and the food industry stop misusing antibiotics, such as for promoting animal growth and preventing disease in healthy animals, in order to preserve the effectiveness of antibiotics for human medicine [22]. Moreover, the increasing demand for organic food has increased the interest in substituting these chemicals with natural products, which do not damage the host or the environment $[23,24]$. Thus, studies of natural compounds with antimicrobial properties are warranted. There is currently much interest in the use of organic acids as 'environmentally friendly' sanitizers or preservatives [25], most notably citric acid, acetic acid and lactic acid [26]. Studies have mainly focused on citric acid, which can be used alone or alongside conventional sanitizers and other alternative technologies [27]. It is especially useful for fruit, such as strawberries [27]. However, it has been noted that organic acids, such as formic acid, lactic acid, propionic acid and their salts, often fail to provide the desired result when applied in practice, such as when used for decontaminating animal feed, thus occasioning substantial additional costs for operators (feed producers and farmers) [28]. Therefore, there is currently much interest in research on alternative organic acids that are both cheap and safe to use.

Myo-inositol 1, 2, 3, 4, 5, 6-hexakisphosphate (IP6), commonly known as phytic acid, is a naturally occurring compound that is 'generally recognized as safe', according to the U.S. Food and Drug Administration classification [29]. It represents the principal storage form of phosphorus $(\mathrm{P})$ in whole cereals and other edible vegetable seeds, such as legumes and nuts, and may account for $65-85 \%$ of the total P in seeds [29]. IP6 is a negatively charged compound that has been considered an anti-nutrient since it acts as a strong chelator of vital minerals like calcium, iron, magnesium, copper, zinc, and potassium, reducing their absorption and bioavailability [30]. 
However, several recent studies in both humans and animals have demonstrated that this natural molecule acts as a disease-preventing compound [31]. Indeed, IP6 displays a broad range of pharmaceutical properties, including antioxidant [32,33], neuroprotective [34, 35], anti-inflammatory [36], lipid lowering [37], pathological calcification preventing [38, 39] and anticancer activities [40-42]. In addition, Kim and Rhee [21] described the anti-biofilm effect of IP6 against E. coli O157:H7, especially when combined with $\mathrm{NaCl}$. They suggested that a sanitizer that combines these two naturally occurring antimicrobial agents could be used by food safety managers who encounter thick biofilm formation in food processing environments.

The purpose of the present work is to assess the effectiveness of IP6 against several foodborne bacterial pathogens for the first time. This is achieved by: (i) determining the minimum inhibitory concentration (MIC) as compared to citric acid (CA); (ii) measuring the inhibition diameters of each indicator bacteria growth inhibition or reduction, and (iii) illustrating the mode of action of IP6 for inhibiting pathogen growth.

\section{Materials and methods}

\subsection{Substrates and chemicals}

Phytic acid solution [myo-Inositol hexakis (dihydrogen phosphate); IP6] was purchased from Sigma-Aldrich (593648; 50\% (w/w) in water). Citric acid (CA), $\left(\mathrm{C}_{6} \mathrm{H}_{8} \mathrm{O}_{7}\right.$; CAS: 77-92-9), was purchased from Fluka, Switzerland.

\subsection{Bacterial strains, media and culture conditions}

The target bacterial strains were obtained from international culture collections (ATCC). They included Gram-positive bacteria: Listeria monocytogenes ATCC 19117 and Staphylococcus aureus ATCC 6538; and Gram-negative bacteria: Salmonella Typhimurium ATCC 14028, Pseudomonas aeruginosa ATCC 49189 and Escherichia coli ATCC 8739. These strains were used as indicator microorganisms for the antibacterial activity assays. L. monocytogenes ATCC 19117 was cultured on Polymyxin Acriflavin Lithium-Chloride Ceftazidime Aesculin Mannitol (PALCAM, LAB M Ltd, U.K) at $37^{\circ} \mathrm{C}$ for 24 h. S. aureus ATCC 6538 was grown on Chapman medium (Oxoid, Basingstoke, Hampshire, UK) at $37^{\circ} \mathrm{C}$ for $24 \mathrm{~h}$, and $S$. Typhimurium ATCC 14028 was cultivated on Xylose Lysine Deoxycholate (XLD, Oxoid) at $37^{\circ} \mathrm{C}$ for $24 \mathrm{~h}$. For the antagonist tests, the final inoculum concentration used for each indicator bacterium was $10^{6}$ colony-forming units of bacteria per milliliter (CFU/ml) as used in the method described by Smaoui et al. [24].

\subsection{Determination of minimum inhibitory concentrations}

The minimum inhibitory concentration (MIC) values, representing the lowest concentration of IP6 and CA at which the microorganism did not demonstrate visible growth after incubation, were determined against a panel of five bacteria, as described by Gulluce et al. [43] with minor modifications. The test was performed in sterile 96 -well microplates with a final volume of $100 \mu \mathrm{l}$ per well. A commercial stock solution of IP6 (50\% (w/w) in water) and a stock solution of CA at $50 \%(w / w)$ in water were used. Then, the corresponding concentrations of IP6 and CA were transferred to each successive well in order to obtain a two-fold serial dilution of the original sample. In fact, each sample was dissolved to a final concentration of $0.078,0.156$, $0.312,0.625,1.25,2.5,5,10$ and $20 \mathrm{mg} / \mathrm{mL}$ and then filtered through $0.22 \mu \mathrm{m}$ pore-size black polycarbonate filters (Millipore). To each test well $10 \mu \mathrm{l}$ of cell suspension were added to final inoculum concentration of $10^{6} \mathrm{CFU} / \mathrm{ml}$ of bacterium. Positive growth control well consisted of Listeria monocytogenes ATCC 19117, Staphylococcusaureus ATCC 6538 and Salmonella Typhimurium ATCC 14028 respectively growth in PALCAM, Chapman and XLD. Plates were 
then covered with the sterile plate covers and incubated at $37^{\circ} \mathrm{C}$ for $24 \mathrm{~h}$. As an indicator of microorganism growth, $25 \mu \mathrm{l}$ of thiazolyl blue tetrazolium bromide (MTT) indicator solution $(0.5 \mathrm{mg} / \mathrm{ml})$ dissolved in sterile water was added to the wells and incubated at $37^{\circ} \mathrm{C}$ for $30 \mathrm{~min}$. The colourless tetrazolium salt acts as an electron acceptor and was reduced to a red-coloured formazan product by biologically active organisms. Where microbial growth was inhibited, the solution in the well remained clear after incubation with MTT. The determination of MIC values was done in triplicate.

\subsection{Agar diffusion method}

The antimicrobial activity of IP6 was evaluated by means of agar-well diffusion assays, as described by Valgas et al. [44]. Fifteen milliliters of the molten agar $\left(45^{\circ} \mathrm{C}\right)$ were poured into sterile petri dishes $\left(\varnothing 90 \mathrm{~mm}\right.$ ). Working cell suspensions were prepared at $10^{6} \mathrm{CFU} / \mathrm{mL}$, and $100 \mu \mathrm{l}$ was evenly spreaded onto the surface of the agar plates of Luria-Bertani (LB) agar (Oxoid Ltd, UK). Once the plates had been aseptically dried, $06 \mathrm{~mm}$ wells were punched into the agar with a sterile Pasteur pipette. IP6 was dissolved in water to a final concentration of 50 $\mathrm{mg} / \mathrm{ml}$ and then filtered through $0.22 \mu \mathrm{m}$ pore-size black polycarbonate filters (Millipore). Thus, $50 \mu \mathrm{l}$ were placed into the wells and the plates were incubated at $37^{\circ} \mathrm{C}$ for $24 \mathrm{~h}$ for bacterial strains. Antibacterial activity was evaluated by measuring the diameter of circular inhibition zones around the well. The un-inoculated media were also tested for inhibitory zones as a control. Tests were performed in triplicate.

\subsection{Mode of action of phytic acid}

The bacteriostatic or bactericidal mode of action of IP6 was tested using a method described previously by Jiang et al. [45]with some modifications. L. monocytogenes ATCC 19117, S. aureus ATCC 6538 and S. Typhimurium ATCC 14028 were cultivated in $100 \mathrm{~mL}$ of PALCAM, Chapman broth and xylose lysine xeoxycholate (XLD) broth, respectively. After $3 \mathrm{~h}$ of incubation, the bacterial growth reached the beginning of the exponential phase (about $10^{6} \mathrm{CFU} / \mathrm{ml}$ ). At this moment, IP6 was added to the cultures at a final concentration of $1 \times \mathrm{MIC}, 2 \times \mathrm{MIC}$ and $4 \times \mathrm{MIC}$. The three indicator strains grown in the absence of IP6 were used as controls. Changes in the turbidity of the cultures were recorded at $\mathrm{OD}_{600 \mathrm{~nm}}$ and the number of $\mathrm{CFU} / \mathrm{mL}$ was determined by plating the serial decimal dilutions of samples on PALCAM agar for L. monocytogenes ATCC 19117, Champan agar for S. aureus ATCC 6538, and XLD agar for S. Typhimurium ATCC 14028, and then counting the colonies that appeared.

\subsection{Statistical analyses}

Measurements were carried out in triplicate and repeated three times. A one-way analysis of variance (ANOVA) was run for each parameter using the SPSS 19 statistical package (SPSS Ltd., Woking, UK). Means and standard errors were calculated and a probability level of $P<0.05$ was used for assessing the statistical significance of the experimental data. Tukey's post hoc test was used to determine whether differences between each of the mean values were significant $(P<0.05)$. Plate count data were converted to logarithms prior to the statistical analyses. Linear mixed models were used, which made certain assumptions about the errors (e.g. constant variance), to compare the CFU values among treatments with different incubation times (measured in h). Mixed models were fitted using SPSS 19 and followed by post hoc contrasts through the origin. The interpretation of the statistical output by analysis of covariance (ANCOVA, SPSS; covariates, time and trial) of a mixed model requires an understanding of how to explain the relationships among the fixed and random effects in terms of the hierarchy levels. The significance or not of all estimates was confirmed by Wald Z. 


\section{Results and discussion}

\subsection{Assessment of the antibacterial activity of phytic acid}

The antibacterial activity of phytic acid (IP6) was evaluated against Gram-positive (L. monocytogenes ATCC 19117 and S. aureus ATCC 6538) and Gram-negative (S. Typhimurium ATCC 14028, P. aeruginosa ATCC 49189 and E. coli ATCC 8739) foodborne bacterial pathogens. The antagonistic activity was assessed by determining the MIC values in comparison with CA and by measuring the inhibition zones by agar diffusion method.

3.1.1 Determination of MIC values of phytic acid and citric acid. The comparison of the antimicrobial activity of IP6 and CA against both Gram-negative and Gram-positive bacteria, as determined using the MIC values, is illustrated in Fig 1. We found that the IP6 MIC ranged from 0.244 to $0.976 \mathrm{mg} / \mathrm{ml}$, while the CA MIC ranged from 1.25 to $2.5 \mathrm{mg} / \mathrm{ml}$. For the Gram-positive bacteria, the IP6 MIC and the CA MIC ranged from 0.488 to 0.976 $\mathrm{mg} / \mathrm{ml}$ and from 1.25 to $2.5 \mathrm{mg} / \mathrm{ml}$, respectively. The lowest MIC values were for S. aureus ATCC 6538. For the Gram-negative bacteria, the IP6 MICs were reduced by at least 50\%, while the CA MIC remained the same as that observed for S. aureus ATCC 6538 (1.25 mg/ $\mathrm{ml})$. No significant $(P>0.05)$ difference was observed in terms of the IP6 MIC and CA MIC $(0.244 \mathrm{mg} / \mathrm{ml}$ and $1.25 \mathrm{mg} / \mathrm{ml}$, respectively) between the three Gram-negative bacteria (Fig 1).

These results indicate that IP6 is more efficient than CA against foodborne pathogenic bacteria (Gram-positive and Gram-negative bacteria).

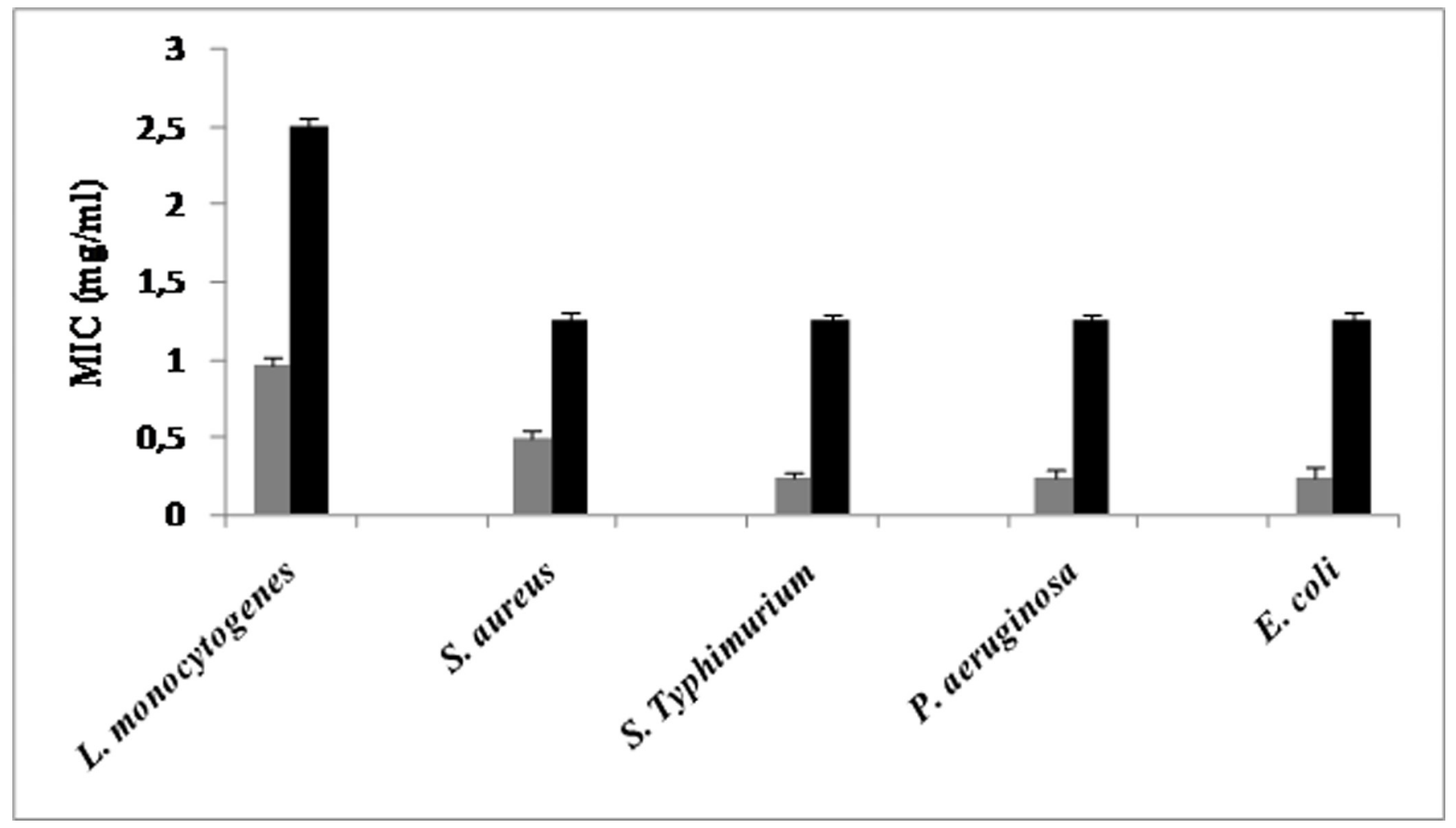

Fig 1. Minimum inhibitory concentration of IP6 ( $\square$ ) and CA $(\square)$ against indicator strains (L. monocytogenes ATCC 19117, S. aureus ATCC 6538, S. Typhimurium ATCC 14028, P. aeruginosa ATCC 49189 and E. coli ATCC 8739.). Values represent the means of triplicate experiments with comparable results.

https://doi.org/10.1371/journal.pone.0231397.g001 




Fig 2. Diameter inhibition zone of IP6 against L. monocytogenes ATCC 19117(口), S. aureus ATCC $6538(\square)$ and S. Typhimurium ATCC 14028( \). Values represent the means of triplicate experiments with comparable results.

https://doi.org/10.1371/journal.pone.0231397.g002

3.1.2. Diameter inhibition assay of phytic acid. The results of the diameter inhibition assays that assessed the antibacterial effects of IP6 are shown in Fig 2. For all of the tested concentrations, this natural compound had an antagonistic effect on all indicator strains tested. The diameter of the inhibition zones generally increased with higher IP6 concentrations $(P$ $<0.05)$. Furthermore, IP6 showed a strong inhibitory $(P<0.05)$ effect and varying degrees of antibacterial activity against all of the strains tested, and the inhibition zones were in the range of $8.25-26.75 \mathrm{~mm}$. At a concentration of $50 \mathrm{mg} / \mathrm{ml}$, the largest diameters were recorded for $S$. aureus and $S$. Typhimurium while L. monocytogenes exhibited the smallest diameter. In general, the inhibition zones evolved exponentially $(P<0.05)$ and, then, not significantly $(P>0.05)$ between 34.16 and $50 \mathrm{mg} / \mathrm{ml}$.

Discs containing $50 \mathrm{mg} / \mathrm{ml}$ of IP6 showed the largest mean inhibition zone diameter against S. aureus, while the discs containing $0.25 \mathrm{mg} / \mathrm{ml}$ showed the smallest diameter. The inhibition zones recorded for IP6 concentrations between 12.5 and $40 \mathrm{mg} / \mathrm{ml}$ were $24.5 \mathrm{~mm}$ in diameter. As the diameter remained the same $(P>0.05)$ this clearly demonstrates that IP6 at $12.5 \mathrm{mg} / \mathrm{ml}$ brought about a significant $(P<0.05)$ reduction in terms of the $S$. aureus counts. We also found that the inhibitory action of IP6 against $S$. Typhimurium ATCC 14028 was comparable to that of $S$. aureus ATCC 6538. Indeed, this inhibition started from a low concentration of IP6 $(1.22 \mathrm{mg} / \mathrm{ml})$ and stabilized $(P>0.05)$ at $34.16 \mathrm{mg} / \mathrm{ml}$. However, for L. monocytogenes ATCC 19117 , the antagonistic activity of IP6 was only observed from a concentration of $10 \mathrm{mg} / \mathrm{ml}$.

Values with a different letter $(\mathrm{a}-\mathrm{c})$ of a same IP6 concentration are significantly different $(P<0.05)$.

Values with a different letter (A-E) of a same diameter inhibition zone are significantly different $(P<0.05)$ 


\subsection{Mode of action of phytic acid}

3.2.1. Effect of the dose of phytic acid on the growth of L. monocytogenes, S. aureus and $S$. Typhimurium in vitro using a linear model (ANOVA). To investigate the effects of varying IP6 dose on L. monocytogenes, S. aureus and S. Typhimurium, the bacterial growth was followed over $24 \mathrm{~h}$ and evaluated in comparison with the control culture (without addition of IP6), following the protocol developed by Jiang et al. [45]. IP6 was added to L. monocytogenes ATCC 19117, S. aureus ATCC 6538 and S. Typhimurium ATCC 14028cells after $3 \mathrm{~h}$ of incubation, when growth reached the beginning of the exponential phase (cell density of about $10^{6}$ $\mathrm{CFU} / \mathrm{ml}$ ). Fig $3 \mathrm{~A}, 3 \mathrm{~B}$ and $3 \mathrm{C}$ shows that when $1 \times \mathrm{MIC}, 2 \times \mathrm{MIC}$ and $4 \times \mathrm{MIC}$ of IP6 were added, a significant downward trend $(P<0.05)$ in the viable count was observed and to some extent was dose-dependent. These results indicate that IP6 has a bactericidal activity against L. monocytogenes ATCC 19117, S. aureus ATCC 6538 and S. Typhimurium ATCC 14028. In fact, for L. monocytogenes ATCC 19117 and S. aureus ATCC 6538, a rapid killing action occurred one hour after the addition of $1 \times \mathrm{MIC}, 2 \times \mathrm{MIC}$ and $4 \times \mathrm{MIC}$ of IP6 (incubation time of $4 \mathrm{~h}$ ) with 1.2, $1.45,4.29$ and $4.57 \log _{10}$ reductions in the density of the cells. The inhibition of growth even persisted $21 \mathrm{~h}$ after the addition of IP6. For the control culture, we noted an increase in the number of viable cells cultured in the absence of IP6 at $24 \mathrm{~h}$ of incubation $\left(10^{13} \mathrm{CFU} / \mathrm{ml}\right.$ for $L$. monocytogenes ATCC 19117, $10^{9} \mathrm{CFU} / \mathrm{ml}$ for S. aureus ATCC 6538 and $10^{7} \mathrm{CFU} / \mathrm{ml}$ for $S$. Typhimurium ATCC 14028). Interestingly, the early logarithmic growth phase of $S$.
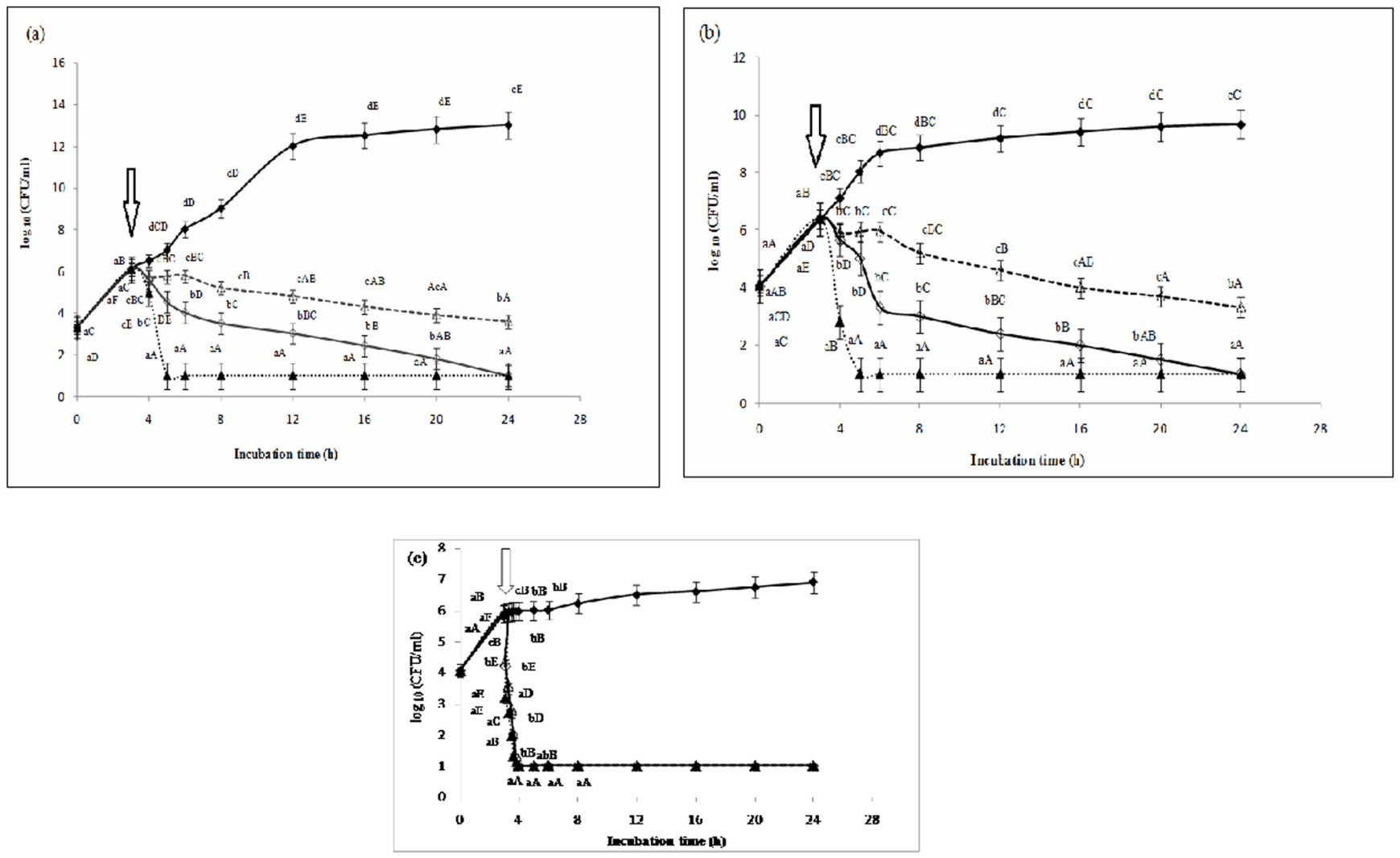

Fig 3. Influence of the dose of IP6 on the growth of L. monocytogenes ATCC 19117 (a), S. aureus ATCC 6538(b) and S. Typhimurium ATCC 14028 (c) in vitro using a linear model (ANOVA).

https://doi.org/10.1371/journal.pone.0231397.g003 
Table 1. L. monocytogenes ATCC 19117, S. aureus ATCC 6538 and S. Typhimurium ATCC 14028 behavior estimates of treatment (Trial) fixed effects.

\begin{tabular}{|c|c|c|c|c|c|c|c|}
\hline Parameter & Estimate & Std. Error & df & $T$ & Sig. & LowerBound & LowerBound \\
\hline \multicolumn{8}{|c|}{ Listeria monocytogenes ATCC19117 } \\
\hline Intercept & 12.195532 & 1.836295 & 15.000 & 6.641 & $0.000(* * *)$ & 8.281562 & 16.109502 \\
\hline Hour 0 (time of IP6 addition) & -6.105627 & 2.596913 & 15.000 & -2.351 & $0.023\left(^{*}\right)$ & -11.640817 & -0.570438 \\
\hline Hour 1 (post IP6 addition) & -5.254537 & 2.596913 & 15.000 & -2.023 & $0.029\left(^{*}\right)$ & -10.789727 & 0.280652 \\
\hline Hour 2(post IP6 addition) & -2.815143 & 2.596913 & 15.000 & -1.084 & $0.044\left(^{*}\right)$ & -8.350332 & 2.720047 \\
\hline Hour 3(post IP6 addition) & -2.103050 & 2.596913 & 15.000 & -0.810 & $0.131(\mathrm{~ns})$ & -7.638239 & 3.432139 \\
\hline Hour 21(post IP6 addition) & $0^{\mathrm{a}}$ & 0 & $\cdot$ & . & . & & . \\
\hline Trial & -2.959106 & 0.553664 & 15.000 & -5.345 & $0.069(\mathrm{~ns})$ & -4.139213 & -1.779000 \\
\hline Hour $0 \times$ Trial & 2.959106 & 0.782999 & 15.000 & 3.779 & $0.002\left({ }^{* *}\right)$ & 1.290184 & 4.628029 \\
\hline Hour $1 \times$ Trial & 2.443571 & 0.782999 & 15.000 & 3.121 & $0.017\left({ }^{*}\right)$ & 0.774649 & 4.112493 \\
\hline Hour $2 \times$ Trial & 0.984288 & 0.782999 & 15.000 & 1.257 & $0.027\left(^{*}\right)$ & -0.684635 & 2.653210 \\
\hline Hour $3 \times$ Trial & 0.781291 & 0.782999 & 15.000 & 0.998 & $0.134(\mathrm{~ns})$ & -0.887631 & 2.450214 \\
\hline Hour $21 \times$ Trial & $0^{\mathrm{a}}$ & 0 & . & . & . & & . \\
\hline \multicolumn{8}{|c|}{ Staphylococcus aureus ATCC 6538} \\
\hline Intercept & 9.402978 & 1.440860 & 15.000 & 6.526 & $0.000\left(^{* * *}\right)$ & 6.331858 & 12.474098 \\
\hline Hour 0 & -3.028230 & 2.037683 & 15.000 & -1.486 & $0.031\left(^{*}\right)$ & -7.371449 & 1.314990 \\
\hline Hour 1 & -0.928906 & 2.037683 & 15.000 & -0.456 & $0.049\left(^{*}\right)$ & -5.272125 & 3.414314 \\
\hline Hour 2 & 0.995682 & 2.037683 & 15.000 & 0.489 & 0.249 (ns) & -3.347537 & 5.338902 \\
\hline Hour 3 & 1.181910 & 2.037683 & 15.000 & 0.580 & $0.611(\mathrm{~ns})$ & -3.161310 & 5.525129 \\
\hline Hour 21 & $0^{\mathrm{a}}$ & 0 & . & . & . & & . \\
\hline Trial & -2.267845 & 1.058362 & 528.35 & -2.143 & $0.075(\mathrm{~ns})$ & -4.346960 & -0.188731 \\
\hline Hour $0 \times$ Trial & 2.267845 & 1.496750 & 528.35 & 1.515 & $0.013\left({ }^{*}\right)$ & -0.672467 & 5.208157 \\
\hline Hour $1 \times$ Trial & 1.043681 & 1.496750 & 528.35 & 0.697 & $0.039\left(^{*}\right)$ & -1.896631 & 3.983994 \\
\hline Hour $2 \times$ Trial & 0.067139 & 1.496750 & 528.35 & 0.045 & $0.254(\mathrm{~ns})$ & -2.873173 & 3.007451 \\
\hline Hour $3 \times$ Trial & -0.063827 & 1.496750 & 528.35 & -0.043 & 0.566 (ns) & -3.004139 & 2.876485 \\
\hline Hour $21 \times$ Trial & $0^{\mathrm{a}}$ & 0 & & - & . & & . \\
\hline \multicolumn{8}{|c|}{ Salmonella Typhimurium ATCC 14028} \\
\hline Intercept & 6.683287 & 2.171377 & 15.000 & 3.078 & $0.008(* *)$ & 2.055107 & 11.311466 \\
\hline Hour 0 & -0.802473 & 3.070790 & 15.000 & -0.261 & $0.010\left(^{*}\right)$ & -7.347707 & 5.742761 \\
\hline Hour 1 & -1.983238 & 3.070790 & 15.000 & -0.646 & $0.044\left(^{*}\right)$ & -8.528472 & 4.561996 \\
\hline Hour 2 & -2.442463 & 3.070790 & 15.000 & -0.795 & $0.065(\mathrm{~ns})$ & -8.987697 & 4.102771 \\
\hline Hour 3 & -2.425511 & 3.070790 & 15.000 & -0.790 & 0.249 (ns) & -8.970746 & 4.119723 \\
\hline Hour 21 & $0^{\mathrm{a}}$ & 0 & & . & . & & . \\
\hline Trial & -1.670822 & 8.797076 & 488978 & -0.190 & $0.104(\mathrm{~ns})$ & -18.912811 & 15.571168 \\
\hline Hour $0 \times$ Trial & 1.670822 & 12.44094 & 488978 & 0.134 & $0.016\left({ }^{*}\right)$ & -22.713034 & 26.054677 \\
\hline Hour $1 \times$ Trial & 0.495809 & 12.44094 & 488978 & 0.040 & $0.033\left({ }^{*}\right)$ & -23.888046 & 24.879665 \\
\hline Hour $2 \times$ Trial & 0.610616 & 12.44094 & 488978 & 0.049 & 0.226 (ns) & -23.773240 & 24.994471 \\
\hline Hour $3 \times$ Trial & 0.606378 & 12.44094 & 488978 & 0.049 & 0.346 (ns) & -23.777478 & 24.990233 \\
\hline Hour $21 \times$ Trial & $0^{\mathrm{a}}$ & 0 & & . & . & & . \\
\hline
\end{tabular}

${ }^{\mathrm{a}}$ :This parameter is set to zero because it is redundant.

Std. Error: standard error; df: The degrees of freedom; t: the Student t-statistic; Sig.: the p-value (associated with the correlation).ns: $P>0.05$;

${ }^{*} P<0.05$

${ }^{* *} P<0.01$

${ }^{* * *} P<0.001$.

https://doi.org/10.1371/journal.pone.0231397.t001

Typhimurium ATCC 14028 resulted in a rapid decrease in a period of less than one hour. It should be noted that this is the first time that it has been shown that IP6 alone can completely 
prevent the growth of foodborne bacterial pathogens such as L. monocytogenes, S. aureus and $S$. Typhimurium. This stands in contrast to the study carried out by Bari et al. (2005), which showed that the combination of nisin $(50 \mu \mathrm{g} / \mathrm{ml})-\mathrm{IP6}(0.02 \%)$ and nisin-pediocin (100 AU/ $\mathrm{ml}$ )-IP6 caused significant reductions in L. monocytogenes growth, but the total inactivation of the foodborne pathogen was not achieved by either the individual or the combined application of these antimicrobial agents. This could be due to the lower concentration of IP6 used in their study $(0.02 \%)$ [46]. Taken together, our results indicate that IP6 exerts a dose-dependent bactericidal effect. According to Kim and Rhee [21], this effect might by due to the strong chelating capacity of IP6. Indeed, IP6 contains six reactive phosphate groups, which are responsible for its strong chelating capacity $[21,47]$.

Viable cell counts $\log _{10}(\mathrm{CFU} / \mathrm{ml})$ in the absence (Control: ) and in the presence of $1 \times \mathrm{MIC}$ $(\triangle), 2 \times$ MIC $(\diamond)$ and $4 \times$ MIC $(\Delta)$ of IP6. The time of addition of IP6 (incubation time of $3 \mathrm{~h}$ ) is indicated by an arrow.

Values represent the means of triplicate experiments with comparable results.

Values with a different letter $(\mathrm{a}-\mathrm{d})$ of a same incubation time are significantly different $(P<$ 0.05).

Values with a different letter (A-F) of a same IP6 dose are significantly different $(P<0.05)$

3.2.2 Effect of the dose of phytic acid on the growth of L. monocytogenes, S. aureus and $S$. Typhimurium in vitro using a general linear model (ANCOVA). Analysis of covariance (ANCOVA) is a general linear model (GLM) that combines ANOVA with linear regression [48]. Descriptive statistics of the mixed model for the time-related survival of L. monocytogenes, S. aureus and S. Typhimurium(in PALCAM, Chapman and XLD broths, respectively) following treatment with various concentrations of IP6 are presented in Tables 1 and 2. The tests of fixed effects have an ANOVA-style test for each fixed effect in the model. This means that a single overall test can be used to assess the usefulness of a given explanatory variable, without focusing on individual levels. Explanatory variables that do not have a significant fixed effect can be removed and then the mixed effect analysis can be rerun using a simpler model with fewer explanatory variables (see Tables 1 and 3). ANCOVA was used to examine the differences in the means of the dependent variables. The independent variables were the six sampling times $(0,1,2,3$ and $21 \mathrm{~h}$ post IP6 addition), and the four treatments (Trial 1: Control samples, Trial 2: $1 \times \mathrm{MIC}$, Trial 3: $2 \times \mathrm{MIC}$ and Trial 4: $4 \times \mathrm{MIC})$. As shown in Table 1, for L. monocytogenes, a significant effect $(P<0.05)$ was found at $0(P=0.023), 1(P=0.029)$ and $2 \mathrm{~h}(P=0.044)$. In contrast, for $S$. aureus, and $S$. Typhimurium the most significant $P$ values were observed at $0 \mathrm{~h}(P=0.031$ and $\mathrm{P}=0.010$, respectively) and 1 hour $(P=0.049$ and $\mathrm{P}=0.044$, respectively). A significant interaction $(P<0.05)$ between the treatments (all trials) and the bacterial growth time was

Table 2. Estimates of covariance parameters in L. monocytogenes ATCC 19117, S. aureus ATCC 6538 and S. Typhimurium ATCC 14028 behavior estimates of treatment (Trial) fixed effects.

\begin{tabular}{|c|c|c|c|c|c|c|}
\hline Parameter & Estimate & Std. Error & Wald Z & $P$. & LowerBound & LowerBound \\
\hline \multicolumn{7}{|c|}{ Listeria monocytogenes ATCC19117 } \\
\hline Residual & 3.065435 & 1.119339 & 2.739 & 0.006 & 1.498571 & 6.270570 \\
\hline TRIAL $[$ subject $=$ ID] Variance & 0.696690 & 23726566.4060 & 0.000 & 0.007 & 0.000000 & \\
\hline \multicolumn{7}{|c|}{ Staphylococcus aureus ATCC 6538} \\
\hline Residual & 1.887343 & .689160 & 2.739 & 0.006 & .922648 & 3.860696 \\
\hline TRIAL $[$ subject $=$ ID] Variance & 17.194269 & 7.59250110 & 0.000 & 0.019 & 0.000000 & \\
\hline \multicolumn{7}{|c|}{ Salmonella Typhimurium ATCC 14028} \\
\hline Residual & 4.286251 & 1.565118 & 2.739 & 0.006 & 2.095380 & 8.767837 \\
\hline TRIAL $[$ subject $=$ ID] Variance & 12.54789 & 257.15489 & 0.000 & 0.012 & 0.000000 & \\
\hline
\end{tabular}

https://doi.org/10.1371/journal.pone.0231397.t002 
Table 3. L. monocytogenes ATCC 19117, S. aureus ATCC 6538 and S. Typhimurium ATCC 14028 behavior estimates of incubation time (h) fixed effects.

\begin{tabular}{|c|c|c|c|c|c|c|c|}
\hline$\underline{\text { Parameter }}$ & Estimate & Std. Error & df & $\mathrm{T}$ & Sig. & LowerBound & LowerBound \\
\hline \multicolumn{8}{|c|}{ Listeria monocytogenes ATCC19117 } \\
\hline Intercept & 3,909020 & 0,957314 & 14,666 & 4,083 & $0.014\left(^{*}\right)$ & 1,864494 & 5,953546 \\
\hline Trial 1 & 3,415564 & 1,218892 & 12,745 & 2,802 & 0.277 (ns) & 0,776946 & 6,054182 \\
\hline Trial 2 & 3,015635 & 1,218892 & 12,745 & 2,474 & $0.122(\mathrm{~ns})$ & 0,377017 & 5,654253 \\
\hline Trial 3 & 2,494664 & 1,218892 & 12,745 & 2,047 & $0.130(\mathrm{~ns})$ & $-0,143954$ & 5,133282 \\
\hline Trial 4 & 0,172542 & 1,218892 & 12,745 & 142 & $0.910(\mathrm{~ns})$ & $-2,466076$ & 2,811161 \\
\hline Hour & $-0,636441$ & 0,342916 & 2,829 & $-1,856$ & $0.022\left(^{*}\right)$ & $-1,766075$ & 0,493193 \\
\hline Trial $1 \times$ Hour & 0,485649 & 0,127775 & 12,745 & 3,801 & $0.021(* *)$ & 0,209046 & 0,762251 \\
\hline Trial $2 \times$ Hour & 0,053229 & 0,127775 & 12,745 & ,417 & $0.008(* *)$ & $-0,223374$ & 0,329831 \\
\hline Trial $3 \times$ Hour & $-0,098872$ & 0,127775 & 12,745 &,- 774 & $0.006(* *)$ & $-0,375474$ & 0,177731 \\
\hline Trial $4 \times$ Hour & $-0,008869$ & 0,127775 & 12,745 &,- 069 & $0.000\left(^{* * *}\right)$ & $-0,285471$ & 0,267733 \\
\hline \multicolumn{8}{|c|}{ Staphylococcus aureus ATCC 6538} \\
\hline Intercept & 3,330309 & 1,001639 & 14,862 & 3,325 & $0.004(* *)$ & 1,193637 & 5,466980 \\
\hline Trial 1 & 4,751291 & 1,299773 & 12,677 & 3,655 & $0.071(\mathrm{~ns})$ & 1,936014 & 7,566569 \\
\hline Trial 2 & 3,670235 & 1,299773 & 12,677 & 2,824 & $0.093(\mathrm{~ns})$ &, 854958 & 6,485513 \\
\hline Trial 3 & 2,967218 & 1,299773 & 12,677 & 2,283 & $0.122(\mathrm{~ns})$ &, 151940 & 5,782495 \\
\hline Trial 4 & 0,077913 & 1,299773 & 12,677 & 0,060 & $0.966(\mathrm{~ns})$ & $-2,737364$ & 2,893191 \\
\hline Hour & $-0,541623$ & 0,307282 & 1,927 & $-1,763$ & $0.049\left(^{*}\right)$ & $-1,913269$ &, 830023 \\
\hline Trial $1 \times$ Hour & 0,267524 & 0,136253 & 12,677 & 1,963 & $0.022\left(^{*}\right)$ &,- 027597 &, 562645 \\
\hline Trial $2 \times$ Hour & 0,007960 & 0,136253 & 12,677 & 0,058 & $0.009(* *)$ &,- 287161 & ,303082 \\
\hline Trial $3 \times$ Hour & $-0,125313$ & 0,136253 & 12,677 & $-0,920$ & $0.001(* *)$ &,- 420434 & , 169808 \\
\hline Trial $4 \times$ Hour & $-0,004005$ & 0,136253 & 12,677 & $-0,029$ & $0.000(* * *)$ &,- 299126 & ,291116 \\
\hline \multicolumn{8}{|c|}{ Salmonella Typhimurium ATCC 14028} \\
\hline Intercept & 4.968089 & 0.753077 & 12.138 & 6.597 & $0,000\left({ }^{* * *}\right)$ & 3.329336 & 6.606842 \\
\hline Trial 1 & 3.683758 & 0.883156 & 11.714 & 4.171 & $0,001\left({ }^{* *}\right)$ & 1.754296 & 5.613219 \\
\hline Trial 2 & $3.90459 \times 10^{-15}$ & 0.883156 & 11.714 & 0.000 & $0.214(\mathrm{~ns})$ & -1.929461 & 1.929461 \\
\hline Trial 3 & $3.94568 \times 10^{-15}$ & 0.883156 & 11.714 & 0.000 & $0.354(\mathrm{~ns})$ & -1.929461 & 1.929461 \\
\hline Trial 4 & $3.94568 \times 10^{-15}$ & 0.883156 & 11.714 & 0.000 & 0.555 (ns) & -1.929461 & 1.929461 \\
\hline Hour & -2.148155 & 0.927415 & 3.026 & -2.316 & $0,031\left({ }^{*}\right)$ & -5.085513 & .789204 \\
\hline Trial $1 \times$ Hour & 0.238283 & 0.092580 & 11.714 & 2.574 & $0,0011\left(^{*}\right)$ & .036020 & .440545 \\
\hline Trial $2 \times$ Hour & $-2.7329 \times 10^{-16}$ & 0.092580 & 11.714 & 0.000 & $0.000\left(^{* * *}\right)$ & -.202263 & .202263 \\
\hline Trial $3 \times$ Hour & $-2.8090 \times 10^{-15}$ & 0.092580 & 11.714 & 0.000 & $0.000\left(^{* * *}\right)$ & -.202263 & .202263 \\
\hline Trial $4 \times$ Hour & $-2.8090 \times 10^{-16}$ & 0.092580 & 11.714 & 0.000 & $0.000\left(^{* * *}\right)$ & -.202263 & .202263 \\
\hline
\end{tabular}

Std. Error: standard error; df: The degrees of freedom; t: the Student t-statistic; Sig.: the p-value (associated with the correlation).ns: $P>0.05$;

${ }^{*} P<0.05$

${ }^{* *} P<0.01$

${ }^{* * *} P<0.001$.

Trial 1: Control (No IP6 added); Trial 2: 1×MIC. Trial 3: $2 \times$ MIC. Trial 4: $4 \times$ MIC.

https://doi.org/10.1371/journal.pone.0231397.t003

shown for 0,1 and $2 \mathrm{~h}$ for L. monocytogenes and for 0 and 1 hour for $S$. aureus and $S$. Typhimurium (Table 1). The results shown in Tables 1 and 2 indicate that the first $\mathrm{h}(0,1$ and 2$)$ are especially important for bacterial growth inhibition. The first $2 \mathrm{~h}$ after adding IP6 would appear to be critical for the inhibition of L. monocytogenes, as after this period, no significant inhibition was found. For S. aureus and S. Typhimurium, growth was inhibited one hour after adding IP6.

The covariance parameters are presented in Table 2. The intercept variances were estimated as 2.554530, 1.572786 and 4.286251 for L. monocytogenes, S. aureus and S. 
Table 4. Estimates of covariance parameters in L. monocytogenes ATCC 19117. S. aureus ATCC 6538 and S. Typhimurium ATCC 14028 behavior estimates of incubation time (h) fixed effects.

\begin{tabular}{|c|c|c|c|c|c|c|}
\hline Parameter & Estimate & Std. Error & Wald $\mathrm{Z}$ & $P$ & LowerBound & LowerBound \\
\hline \multicolumn{7}{|c|}{ Listeria monocytogenes ATCC19117 } \\
\hline Residual & 2.450288 & 0.935779 & 2.618 & 0.009 & 1.159147 & 5.179597 \\
\hline HOUR $[$ subject $=$ ID] Variance & 0.085107 & 0.105096 & 0.810 & 0.041 & 0.007566 & 0.957389 \\
\hline \multicolumn{7}{|c|}{ Staphylococcus aureus ATCC 6538} \\
\hline Residual & 3.501211 & 1.107180 & 3.162 & 0.002 & 1.883843 & 6.507165 \\
\hline HOUR $[$ subject $=$ ID] Variance & 32.26787 & 11.51787 & 0.000 & 0.031 & 0.000000 & . \\
\hline \multicolumn{7}{|c|}{ Salmonella TyphimuriumATCC 14028} \\
\hline Residual & 1,325082 & 0,547535 & 2,420 & 0,016 & 0,589548 & 2,978285 \\
\hline TRIAL $[$ subject $=$ ID] Variance & 3,123839 & 2,784617 & 1,122 & 0,021 & 0,544403 & 17,924910 \\
\hline
\end{tabular}

Typhimurium, respectively (Table 2). The null hypothesis for this parameter is a variance of zero, which would indicate that a random effect is not present. This can be assessed using a statistical test called a Wald Z statistic [49-51]. For L. monocytogenes, S. aureus and S. Typhimurium, this test was run and the null hypothesis (Wald $Z=0.000, P=0.019$ ), (Wald $Z=0.000$, $P=0.007$ ) and (Wald $Z=0.000, P=0.012$ ) was rejected. This suggests that there are important unmeasured explanatory variables that affect the results in a way that appears random because we do not know the values of the missing explanatory variables (Table 2).

The interaction estimates for the differences in slope between trial $4(4 \times \mathrm{MIC})$ and the other trials are shown in Table 2A for the three strains. It is very important to note that the parameter estimates given in the fixed effects are estimates of mean parameters. The effects of the treatments, the bacterial growth time and their interaction on the inhibition of L. monocytogenes, S. aureus and S. Typhimurium are shown in Table 3. A significant interaction $(P<0.05)$ was found between all of the treatments and the bacterial growth time. This was highly significant $(P<0.001)$ for the interaction between trial $4(4 \times \mathrm{MIC})$ and time for L. monocytogenes, $S$. aureus and $S$. Typhimurium(in PALCAM, Chapman and XLD media, respectively) (Table 3). These results show that high concentrations of IP6 coupled with incubation time actively inhibit the studied bacteria. Interestingly, for $S$. Typhimurium, $1 \times$ MIC of IP6 is sufficient for bacterial inhibition.

As presented in Table 4, for L. monocytogenes, S. aureus and $S$. Typhimurium, the intercept variances ((Wald $\mathrm{Z}=0.810, P=0.041$ ), (Wald $\mathrm{Z}=0.000, P=0.031$ ) and (Wald $\mathrm{Z}=0.000$, $P=0.021)$ ) were found to be greater than zero (Table 4). The results shown in Tables 3 and 4 show that there are interactions between the trial and incubation time for L. monocytogenes, $S$. aureus and $S$. Typhimurium.

\section{Conclusion}

In this study, we demonstrated for the first time the strong inhibitory effect of phytic acid (IP6) against the proliferation of both Gram-positive and Gram-negative foodborne pathogenic bacteria. This was achieved by determining the MIC values and diameter inhibition assays. Of note, IP6 was found to be especially effective against Gram-negative bacteria and more efficient than citric acid, which is widely used as a natural sanitizer in the food industry to reduce the growth rate of foodborne pathogenic bacteria. The analysis study assessing the mode of action confirms these results and indicates that IP6 exerts a dose-dependent bactericidal effect against L. monocytogenes, S. aureus and S. Typhimurium. 
Taken together, our results reinforce suggestions that IP6, a natural and biodegradable GRAS compound, could be used for the development of future environmentally friendly applications in the food industry.

\section{Supporting information}

S1 Data.

(PDF)

\section{Acknowledgments}

This work was supported by the Tunisian Government (Contract Program LMB-CBS, 20152018) and by the University of Jeddah (Saudi Arabia) through the International Cooperation Grant Research Project N UJ-02-009-ICGR.

The authors acknowledge Prof. Pierfrancesco Cerruti (Institute for Polymers, Composites and Biomaterials, Pozzuoli-Italy) for critical reading of the manuscript and collaboration.

\section{Author Contributions}

Conceptualization: Hichem Chouayekh.

Data curation: Ines Boukhris.

Formal analysis: Ines Boukhris, Slim Smaoui, Karim Ennouri, Hichem Chouayekh.

Funding acquisition: Othman A. Alghamdi.

Investigation: Ines Boukhris.

Methodology: Ines Boukhris, Slim Smaoui, Nawres Morjene.

Project administration: Hichem Chouayekh.

Resources: Hichem Chouayekh.

Software: Slim Smaoui, Karim Ennouri.

Supervision: Slim Smaoui.

Validation: Ines Boukhris, Slim Smaoui.

Visualization: Ines Boukhris, Slim Smaoui.

Writing - original draft: Ines Boukhris, Slim Smaoui, Karim Ennouri, Ameny Farhat-Khemakhem, Monia Blibech, Othman A. Alghamdi.

Writing - review \& editing: Ines Boukhris, Slim Smaoui, Ameny Farhat-Khemakhem, Monia Blibech, Othman A. Alghamdi, Hichem Chouayekh.

\section{References}

1. Havelaar AH, Kirk MD, Torgerson PR, Gibb HJ, Hald T, Lake RJ, et al. World Health Organization global estimates and regional comparisons of the burden of foodborne disease in 2010. PLoS Med. 2015; 12.

2. Bhaskar SV.Foodborne diseases-disease burden. In Food Safety in the $21^{\text {st }}$ Century. Academic Press; 2017. pp. 1-10.

3. Mathipa MG, Bhunia AK, Thantsha MS.Internalin AB-expressing recombinant Lactobacillus casei protects Caco-2 cells from Listeria monocytogenes-induced damages under simulated intestinal conditions.PLoS One. 2019; 14(7). 
4. Lee C, Kim MI, Park J, Hong M.Structure-based molecular characterization and regulatory mechanism of the LftR transcription factor from Listeria monocytogenes: Conformational flexibilities and a ligandinduced regulatory mechanism. PLoS One. 2019; 14(4).

5. ColagiorgiA Bruinil, Di CiccioPA ZanardiE, GhidiniS lanieriA. Listeria monocytogenes biofilms in the wonderland of food industry. Pathogens.2017; 6:41-49.

6. Vu HTK, Benjakul S, Vongkamjan K. Characterization of Listeria prophages in lysogenic isolates from foods and food processing environments.PLoS One. 2019; 14(4).

7. Ferreira $S$ and Domoingues $F$. The antimicrobial action of resveratrol against Listeria monocytogenes in food-based models and and its antibiofilm properties. J Sci Food Agric. 2016; 96: 4531-4535. https:// doi.org/10.1002/jsfa.7669 PMID: 26867522

8. KalaniBS IrajianG, LotfollahiL AbdollahzadehE RazaviS. Putative type II toxin-antitoxin systems in Listeria monocytogenes isolated from clinical, food, and animal samples in Iran. Microb Pathog. 2018; 122: 19-24. https://doi.org/10.1016/j.micpath.2018.06.003 PMID: 29879433

9. Chen YI, Burall LS, Macarisin D, Pouillot R, Strain E, De Jesus AJ, et al. Prevalence and level of Listeria monocytogenes in ice cream linked to a Listeriosis outbreak in the United States.J Food Prot. 2016; 79: 1828-1832. https://doi.org/10.4315/0362-028X.JFP-16-208 PMID: 28221903

10. Morach M, Käppeli N, Hochreutener M, Johler S, Julmi J, Stephan R, et al. Microarray based genetic profiling of Staphylococcus aureus isolated from abattoir byproducts of pork origin.PLoS One. 2019; 14 (9).

11. Schubert J, Podkowik M, Bystron J, Bania J. Production of staphylococcal Enterotoxins $D$ and R in milk and meat juice by Staphylococcus aureus strains. Foodborne Pathog Dis. 2017; 14(4): 223-230. https://doi.org/10.1089/fpd.2016.2210 PMID: 28072918

12. Hu WD. Distribution of food-borne Staphylococcus aureus enterotoxin genes. Genet Mol Res.2016;15 (1).

13. Vázquez-Sánchez D, Galvão JA, Oetterer M. Contamination sources, biofilm-forming ability and biocide resistance of Staphylococcus aureus in tilapia-processing facilities. Food Sci Technol Int. 2018; 24:209-222. https://doi.org/10.1177/1082013217742753 PMID: 29169268

14. Doulgeraki AI, Di Ciccio P, Lanieri A, Nychas GE. Methicillin-Resistant Food-related Staphylococcus aureus: A review of current knowledge and biofilm formation for future studies and applications. Res Microbiol. 2017; 168(1): 1-15. https://doi.org/10.1016/j.resmic.2016.08.001 PMID: 27542729

15. Gutiérrez D, Delgado S, Vázquez-Sánchez D, Martínez B, Cabo ML, Rodríguez A, et al. Incidence of Staphylococcus aureus and analysis of bacterial-associated communities on food industry surfaces. Appl Environ Microbiol. 2012; 78:8547-8554. https://doi.org/10.1128/AEM.02045-12 PMID: 23023749

16. Vázquez-Sánchez D, Cabo ML, Ibusquiza PS, Rodríguez-Herrera JJ. Biofilm-forming ability and resistance to industrial disinfectants of Staphylococcus aureus isolated from fishery products. Food Control. 2014; 39:8-16.

17. Nilsson OR, Kari L, Steele-Mortimer O. Foodborne infection of mice with Salmonella Typhimurium. PLoS One. 2019; 14(8).

18. KhabbazRF MoseleyRR, SteinerRJ LevittAM, BellBP. Challenges of infectious diseases in the USA Lancet. 2014; 384: 53-63. https://doi.org/10.1016/S0140-6736(14)60890-4

19. JoshiK MahendranR, AlagusundaramK NortonT, TiwariBK. Novel disinfectants for fresh produce. Trends Food Sci Technol. 2013; 34:54-61.

20. Chen JH, Ren Y, Seow J, Liu T, . Bang WS,. Yuk HG. Intervention technologies for ensuring microbiological safety of meat: current and future trends. Compr Rev Food Sci Food Saf. 2012; 11:119-132.

21. Parish ME, Beuchat LR, Suslow TV, Harris LJ, Garrett EH, Farber JN, Busta FF. Methods to reduce/ eliminate pathogens from fresh and fresh-cut produce. Compr Rev Food Sci Food Saf 2003; 2: 161173.

22. World Health Organization (WHO). Strategic and Technical Advisory Group on Antimicrobial Resistance. Report of the first meeting Geneva, Sept 19-20, 2013; http://www.who.int/drugresistance/stag/ amr_stag_meetingreport 0913.pdf (accessed July 14, 2015).

23. Carocho M, Morales P, Ferreira IC. Natural food additives: Quo vadis? Trends in Food Sci Technol. 2015; 45:284-295.

24. Smaoui S, Elleuch L, Ben Salah R, Najah S, Chakchouk-Mtibaa A, Sellem I, et al. Efficient role of BacTN635 on the safety properties, sensory attributes, and texture profile of raw minced meat beef and chicken breast, Food Addit Contam: Part A Chem. Anal. Control Expo. Risk Assess. 2014; 31:218225.

25. Kwon SA, Song WJ, Kang DH. Combination effect of saturated or superheated steam and lactic acid on the inactivation of Escherichia coli O157: $\mathrm{H} 7$, Salmonella Typhimurium and Listeria monocytogenes on 
cantaloupe surfaces. Food microbiology. 2019; 82:342-348. https://doi.org/10.1016/j.fm.2019.03.012 PMID: 31027792

26. Choi MJ,Kim SA, Lee NY, Rhee MS. New decontamination method based on caprylic acid in combination with citric acid or vanillin for eliminating Cronobacter sakazakii and Salmonella enterica serovar Typhimurium in reconstituted infant formula. Int J Food Microbiol. 2013; 166:499-507. https://doi.org/ 10.1016/j.jifoodmicro.2013.08.016 PMID: 24042002

27. Lin CM, Sheu SR, Hsu SC, Tsai YH. Determination of bactericidal efficacy of essential oil extracted from orange peel on the food contact surfaces. Food Control. 2010; 21(12):1710-1715.

28. Axmann S, Kolar V, Adler A, Strnad I. Efficiency of organic acid preparations for the elimination of naturally occurring Salmonella in feed material. Food Addit Contam: Part A Chem. Anal. Control Expo. Risk Assess. 2017; 34:1915-1924.

29. Schlemmer U, Frolich W, Prieto RM, Grases F. Phytate in foods and significance for humans: food sources, intake, processing, bioavailability, protective role and analysis. Mol Nutr Food Res. 2009; 53 S330-S375. https://doi.org/10.1002/mnfr.200900099 PMID: 19774556

30. Raboy V. myo-Inositol-1,2,3,4,5,6-hexakisphosphate. Phytochemistry. 2003; 64: 1033-1043. https:// doi.org/10.1016/s0031-9422(03)00446-1 PMID: 14568069

31. Bhowmik A, Ojha D, Goswami D, Das R, Chandra NS, Chatterjee TK, et al. Inositol hexa phosphoric acid (phytic acid), a nutraceuticals, attenuates iron-induced oxidative stress and alleviates liver injury in iron overloaded mice. 2017. Biomed Phramacother. 2017; 87: 443-450.

32. Canan C, Delaroza F, Casagrande R, Baracat MM, Shimokomaki M, louko Ida E. Antioxidant capacity of phytic acid purified from rice bran. Acta Sci Technol. 2012; 34:457-463.

33. Sakač M, Čanadanović-Brunet J, Mišan A, Tumbas V, Medić D. Antioxidant activity of phytic acid in lipid model system. Food Technol Biotechnol. 2010; 48:524-529.

34. Anekonda TS, Wadsworth TL, Sabin R, Frahler K, Harris C, Petriko B, et al. Phytic acid as a potential treatment for alzheimer's pathology: evidence from animal and in vitro models. J Alzheimers Dis. 2011; 23: 21-35. https://doi.org/10.3233/JAD-2010-101287 PMID: 20930278

35. Xu Q, Kanthasamy AG, Reddy MB. Neuroprotective effect of the natural iron chelator, phytic acid in a cell culture model of Parkinson's disease. Toxicology. 2008; 245: 101-108. https://doi.org/10.1016/j. tox.2007.12.017 PMID: 18255213

36. Goßner S, Yuan F, Zhou C, Tan Y, Shu Q, Engel KH. Impact of Cross-Breeding of low phytic acid MIPS1 and IPK1 soybean (Glycine max L. Merr.) Mutants on their contents of inositol phosphate isomers, J Agric Food Chem. 2018; 67: 247-257. https://doi.org/10.1021/acs.jafc.8b06117 PMID: 30541281

37. Jariwalla RJ. Inositol hexaphosphate (IP6) as an anti-neoplastic and lipid-lowering agent. Anticancer Res. 1999; 19: 3699-3702. PMID: 10625943

38. Grases F, Sanchis P, Perello J, Isern B, Prieto RM, Fernandez-Palomeque C, et al. Phytate (myo-inositol hexakisphosphate) inhibits cardiovascular calcifications in rats. Front Biosci. 2006; 11: 136-142. https://doi.org/10.2741/1786 PMID: 16146720

39. Grases F, Prieto RM, Simonet BM, March JG. Phytate prevents tissue calcifications in female rats. Biofactors. 2000; 11:171-177. https://doi.org/10.1002/biof.5520110303 PMID: 10875304

40. Shamsuddin AM, Vucenik I, Cole KE. IP6: a novel anti-cancer agent. Life Sci. 1997; 61:343-354. https://doi.org/10.1016/s0024-3205(97)00092-1 PMID: 9244360

41. Norhaizan ME, Ng SK, Norashareena MS, Abdah MA. Antioxidant and cytotoxicity effect of rice bran phytic acid as an anticancer agent on ovarian, breast and liver cancer cell lines. Mal J Nutr. 2011; 17: 367-375.

42. Norazalina S, Norhaizan ME, Hairuszah I, Norashareena MS. Anticarcinogenic efficacy of phytic acid extracted from rice bran on azoxymethane-induced colon carcinogenesis in rats. Exp Toxicol Pathol. 2010; 62: 259-268. https://doi.org/10.1016/j.etp.2009.04.002 PMID: 19464858

43. Gulluce M, Sahin F, Sokmen M, Ozer H, Daferera D, Sokmen A, et al. Antimicrobial and antioxidant properties of the essential oils and methanol extract from Mentha longifolia L. ssp. Longifolia. Food Chem. 2007; 103: 1449-1456.

44. Valgas $C$, Souza SMD, Smânia EF, Smânia A Jr. Screening methods to determine antibacterial activity of natural products. Braz J Microbiol 2007; 38: 369-380.

45. Jiang H, Zou J, Cheng H, Fang J, Huang G. Purification, Characterization, and Mode of Action of Pentocin JL-1, a Novel Bacteriocin Isolated from Lactobacillus pentosus, against Drug-Resistant Staphylococcus aureus. BioMed Research International. 2017; 2017:7657190. https://doi.org/10.1155/2017/ 7657190 PMID: 29333451

46. Bari ML,. Ukuku DO, Kawasaki T, Inatsu Y, Isshiki K, Kawamoto S. Combined efficacy of nisin and pediocin with sodium lactate, citric acid, phytic acid, and potassium sorbate and EDTA in reducing the 
Listeria monocytogenes population of inoculated fresh-cut produce. J Food Prot. 2005; 68: 1381-1387. https://doi.org/10.4315/0362-028x-68.7.1381 PMID: 16013374

47. Evans WJ, McCourtney EJ, Shrager RI. Titration studies of phytic acid. J Am Oil Chem Soc. 1982; 59: 189-191.

48. Rutherford A. Introducing ANOVA and ANCOVA: A GLM approach. London: Sage. 2001.

49. Meyers LS, Gamst G, Guarina AJ. Applied multivariate research: Design and interpretation, Sage, Thousand Oaks, CA 2006.

50. Ben Braïek O, Smaoui S, Ennouri K, Morandi S, Cremonesi P, Hani K. RAPD-PCR characterisation of two Enterococcus lactis strains and their potential on Listeria monocytogenes growth behaviour in stored chicken breast meats: Generalised linear mixed-effects approaches. LWT-Food Sci Technol. 2019; 99: 244-253.

51. Ben Braïek O, Smaoui S, Ennouri K, Hani K, Ghrairi T. Genetic Analysis with Random Amplified Polymorphic DNA of the multiple enterocin-producing Enterococcus lactis 4CP3 strain and its efficient role in the growth of Listeria monocytogenes in raw beef meat. Biomed Res Int. 2018, Article ID 5827986, 10 pages. 